\title{
Toleration, Diversity, and Global Justice
}

\author{
Kok-Chor Tan \\ University Park: The Pennsylvania State University \\ Press, 2000. 228 pages.
}

In his book Toleration, Diversity, and Global Justice, Kok-Chor Tan challenges the realist tradition's popularity and its assumption that the state of nature is essentially immoral. Instead, he points to the growing role of international government organizations (e.g., the UN and the EU), which he states indicate morality's global predominance. Centered on the premise of liberalism's primacy - as an ideology and a practice - the book focuses on the philosophical tensions among liberals in terms of liberalism's meaning and scope.

Two questions dominate his analysis: First, what are the limits of liberal toleration, and should liberal states tolerate or criticize nonliberal states in the name of furthering liberalism? Second, is liberalism, based on the idea of individualism, compatible with collectivist cultures or societies? Within this context, the author examines liberalism's domestic and global consequences. Tan notes that if a society is formatted along the parameters of liberalism, then toleration and individualism compliment each other. However, as such compatibility does not exist in nonliberal states, the question becomes one of liberals' morality and responsibility in terms of whether such nonliberal states should be tolerated.

By posing this question, it appears that the author is alluding to the implications of liberalism in the international front, namely, whether liberal states have the jurisdiction to intervene in nonliberal states' matters of domestic jurisdiction. Another question is whether such intervention - in defense of individualism, morality, and autonomy - contradicts the very essence of liberalism, namely, its commitment to autonomy even for nonliberal states. The author phrases the question slightly differently by asking whether liberalism's emphasis on autonomy (defined in individual terms) defines the limits of tolerating nonliberal states.

In addressing the questions surrounding the moral imperative of liberals vis-à-vis nonliberal societies and states, Tan distinguishes between two kinds of liberalism: political liberalism with an overriding emphasis on toleration (acceptance), and a comprehensive liberalism with an overriding emphasis on autonomy and individualism. In other words, those political liberals restrict their concerns only to those "uncontroversial concerns of society." Instead, the concern is on the design of political institutions and, 
as such, on the public - and not the private - realms of society. As a result, political liberalism seems more likely to tolerate nonliberal societies as long as some of its basic minimum standards are met.

Comprehensive liberals, however, do not distinguish between private and/or public spheres, and therefore, assert that liberalism, defined as autonomy and individualism, should be upheld in all realms for toleration to be afforded. The author's central thesis is that nonliberal views and practices may not be accepted under the guise of tolerating others. In fact, he defends comprehensive liberalism. Tan's significant contribution is his assertion that defending comprehensive liberalism is not an attack on cultural diversity. Indeed, he contends that comprehensive liberalism is more conducive to diversity than is political liberalism.

While noting John Rawls' significant contributions in refining contemporary political philosophy, the author takes a contrary stance on Rawls' defense of political liberalism. Chapter 2, devoted entirely to this philosophical dissent, notes that the communitarian basis of Rawls' criticism of comprehensive liberalism is unfounded. Rawls criticizes the universalistic underpinning of comprehensive liberalism in a fashion similar to Michael Walzer. Tan notes Rawls' rather cultural relativist stance in his defense of nonliberal states. He rejects the Rawlsian view that nonliberal states deserve toleration and thus should be extended that privilege as long as one is contending with "decent hierarchical societies."

Chapter 3, "Toleration and Diversity," presents Tan's full-fledged defense of comprehensive liberalism. One pillar of such a defense comprises his argument that Rawls' criticism of comprehensive liberalism is either exaggerated or equally applicable to political liberalism. Tan develops this argument to conclude that, contrary to common wisdom, comprehensive liberalism affords more diversity. He contends that cultural diversity is a product of comprehensive liberalism. One may understand his contention in terms of the fact that despite comprehensive liberalism's universalistic essence, such liberalism encourages diversity by allowing and requiring the autonomy of all, thus leading to an increase - not a decrease - in societal diversity.

Chapter 4, "Individual Rights and State Sovereignty," takes the defense of comprehensive liberalism to the global arena. Tan's assertions in this chapter develop his previous argument, namely, that tolerating different states ought to be limited by the states' commitment to individual rights. The author's main contention is that tolerating diversity is moral as long as diversity is not defined as a lack of individualism. Further, he argues that Rawls' communitarian defense of political liberalism does not apply to the 
global arena, since "few states are moral communities in the way that is required to drive the communitarian argument."

Chapter 5 extends the author's commitment to comprehensive liberalism based on the contention that such a defense does not exclude cultural diversity in the global realm. Thus, while communitarians [such as Walzer and Rawls] criticize comprehensive liberalism on the grounds that "morality is context-dependent," Tan argues that while contexts differ [as represented by different cultures], morality stays the same. Here morality is appreciated as being all-inconclusive - consistent with the comprehensive liberal view - while still appreciating the different contexts within which such morality can be practiced. Hence, the author concludes that comprehensive liberalism, defined within such parameters, is not so radically individualistic as to dilute cultural diversity. Nonetheless, defending comprehensive liberalism in a culturally diverse world breeds a logical criticism: the incompatibility of its assumption of universal morality (defined in terms of individualism) and cultural morality.

Chapter 6 addresses this criticism by contending that any seeming contradictions between the comprehensive liberal view and cultural diversity is really a function of a given society's social inequalities and not an intrinsic incompatibility with individualism and autonomy. Extending this point further, Tan argues in chapter 7 that the problem with political liberalism with its limited scope of moral concern - is that it ignores the existence and consequences of global inequality that, by definition, should be the very concern upon which notions of morality (justification of liberal thought) should be based.

Tan offers a most intriguing analysis of liberalism's philosophical dimensions based on debates surrounding its definition, limits, and purpose. Since he rejects the incompatibility between individualism and cultural diversity, and since he argues that the practice of comprehensive liberalism actually contributes to the flourishing of diversity based on its support of autonomy, his book offers an interesting theoretical framework within which one can analyze Muslim societies and states. This study thus brings to light the dangers of using cultural relativist arguments that justify and legitimize human rights violations on grounds of context-based morality.

Further, the author's argument that comprehensive liberalism encourages (contrary to dilutes) cultural diversity can be used to understand why, in its absence, not only is diversity stifled - here I define diversity in ideological as well as broad cultural terms - but civil unrest fueled. Thus the rise of radical factions in numerous Middle Eastern and Asian states can be seen 
as a cumulative reaction to the discouragement of autonomy and individualism. Indeed, sectarian violence can be explained, in part, as an inevitable conflict when provisions for autonomy and individualism (comerstones of comprehensive liberalism) are absent.

Irm Haleem Visiting Assistant Professor Northeastern University Boston, Massachusetts 